\title{
Herbal Extract as an Ecofriendly Antimicrobial Finishing of Cotton Fabric
}

\author{
A.El-Shafei ${ }^{1}$, S.Shaarawy ${ }^{*}$, F.H.Motawe ${ }^{2}$ and R.Refaei ${ }^{1}$ \\ ${ }^{1}$ National Research Centre (Scopus affiliation ID 60014618), Pre-treatment and \\ Finishing of Cellulosic Fibers Department, Textile Research Division, 33El-Behouth \\ St. (former El-Tahrir str.), Dokki, P.O. 12622, Giza, Egypt \\ ${ }^{2}$ National Research Centre (Scopus affiliation ID 60014618), Microbial Chemistry \\ Department Genetic Engineering and Biotechnology Research Division, 33El- \\ Behouth St. (former El-Tahrir str.), Dokki, P.O. 12622, Giza, Egypt
}

\begin{abstract}
N ECOFRIENDLY antimicrobial finishing agent has been prepared from herbal extracts A. Chamomile, sage and green tea " which have been applied to cotton fabric in presence and absence of free formaldehyde crosslinking agent (Glyoxal) using pad, dry cure method. Antimicrobial properties of treated fabrics have been improved which make it more important and inevitable finish for garments. Therefore, cotton fabric was treated with each antibacterial extract at various concentrations $1,2, \%$ bwf using pad-dry -cure method. Treated fabrics have been evaluated for their antimicrobial activity. The Chamomile, sage and green tea treated fabrics exhibited antimicrobial activity against both gram negative and gram positive bacteria and yeasts unicellular fungi. The treated cotton fabrics have shown an excellent antimicrobial activity even after washing 10 cyclic wash. The samples were examined for SEM and physical properties of cotton including, tensile strength and elongation at break Abrasion Resistance, Water \& air permeability and Stiffness of the fabric. also the treated fabric show very good results for $\mid \mathrm{UV}$ protection.
\end{abstract}

keywords: Ecofriendly antimicrobial finishing, Cotton fabric, Essential oil, Herbal extract.

\section{Introduction}

Textiles are natural polymers of vegetable origin. It has been produced for human, to cover their bodies for temperature, dust, sunlight, wind and external environmental atmosphere. Apparel has an important place in human life, from old time till now through developing newer high technology and interdisciplinary products.

Among technical textiles, medical textiles are a very promising sector, which plays a vital role in health of humanity. It consists of textiles used in operative and post-operative tasks in and around the patient and the medical practitioners. These products are produced either by weaving, knitting, braiding or other nonwoven techniques. Medical textiles are broadly classified as nonimplantable materials, implantable materials, extra corporeal devices, and hygiene products, protective and health care textiles. Health care, disposable and non-disposable hygiene products mainly used in hospitals. The use of such products helps to reduce the opportunity for contamination by biological toxins and infectious pathogens.

Plants and plant product are traditionally used for healing of wounds, burn injuries, anti-fungal, anti-viral, anti-bacterial and anti-microbial activity against skin infections. Herbal plant extract for antimicrobial finishing in textiles because of the excellent antimicrobial and ecofriendly properties exhibited by them.

Nowadays, among the environmental pollution, it is important to develop or find new hygiene products. Nowadays the consumers are demanding eco-friendly products. Hence the research has been carried out to use natural herbal plant extracts for antibacterial finishing in textiles because of the excellent antibacterial properties exhibited by them. Since these natural antibacterial agents are less toxic, less irritant and biodegradable they can be used as an antibacterial finish. 
The antimicrobial bioactive agents have become highly important for bio-functionalization for textile materials because they impart safe nontoxic and environment-friendly properties. As consumers become more aware of hygienic and potentially harmful effects of micro-organisms the demand for antimicrobial finished clothing is increasing. Many plant extracts possessing antibacterial properties can be used as textile finishing agents. [1]

As already settled, natural products particularly derived from plants; on the account of their plenty availability, green approach, low toxicity, biocompatibility and eco-friendly nature are accepting popularity all the world-wide for their utilization in textiles[2,3]. In addition, there are a lot of requests in textile marketing places that provides comfort-ability as well as other functional properties. For that reason; scientists searching in textiles are studying the application's methods possible of the plants containing bioactive agent in producing highly functional value-added and more attractive textile substrates. Insect-repellent[4], deodorizing/aroma[5], UVprotection[6,7] antimicrobial[2,8] and flame retardant[9] are some of the new properties, which have been acquired recently on textiles.

In recent years, the growing demand for herbal products has led to the idea of developing healthcare textile products. The present examination aims at developing an eco-friendly antibacterial finishing agents from plant extracts. Some plants were identified, selective and screened for their antibacterial activities. Their extracts were applied to cotton fabric. Herbal extracts from chamomile leaf, green tea, and sage were selected for this study. The durability of finished cotton to several washing cycles have been studied. As known, herbal extracts shown a good antibacterial property but this property was decreased after washing [10].

The present work focused on prepared and evaluate the extract from chamomile, sage and green tea, as natural antimicrobial textile finishes. These extracts included active ingredients they are rich and contribute to controlling a variety of different diseases, -infections and allergies- but only few studies have been explored for their antimicrobial activity on textile materials.

This research discusses the application of different plant extract herbs on the cotton Egypt.J.Chem. 61, No. 2 (2018) fabric in absence or presence of eco-friendly crosslinking agent (glyoxal) to help fixed it on the fabric, which in turn increase durability of treated cotton fabric to the desired properties, via herbs treatment.

\section{Experimental}

\section{Material}

The desized, scoured and bleached cotton fabric purchased from Mehall-Alkoubra. The fabric was purified by scouring at $100^{\circ} \mathrm{C}$ for $60 \mathrm{~min}$. using a solution containing $\mathrm{Na}_{2} \mathrm{CO}_{3}(2 \mathrm{~g} / \mathrm{l}$, wetting agent, $1 \%$ ), then thoroughly washed with water and dried at ambient conditions. Glyoxal, Aluminuim Sulphate

\section{Methods \\ Herbal plants Collection}

The present works prepared and evaluate the natural antimicrobial textile finishes extracted from chamomile, sage and green tea. The dried plants were purchased from China. The dried plants were converted into fine powder by using dry grinding machine. The extraction process was done in three stages such as drying, grinding and extraction, two types of extraction method were followed, aqueous extraction and methanol extraction was done for all the selected herbs.

\section{Procedure for aqueous extraction}

$10 \mathrm{~g}$ of dried herbal Powder was mixed in 100 $\mathrm{ml}$ of hot water shake in shaking water bath for mixing the herbal powder with hot water at $100^{\circ} \mathrm{C}$ for one hour, after that the extract solution left to cool and then filtered. The filtrate extract was collected and kept in the bottles stored at $4{ }^{\circ} \mathrm{C}$ for further used.

\section{Methanol extraction}

The following procedure was used for the methanol extraction of the selected herbs. 10 $\mathrm{g}$ of the herbal powder was mixing thoroughly with methanol and water $80 / 20 \mathrm{ml}$ and was kept in airtight conical flask. The conical flask was incubated for $24 \mathrm{~h}$ in the room temperature. The supernatant was filtered and the filtrate was dried then the methanol was evaporated in the room temperature when exposed to the air. The filtrate was collected and kept in an airtight bottle at $4{ }^{\circ} \mathrm{C}$ for further used.

\section{Cotton Fabric Treatment with Herbal Prod-} ucts

The cotton fabric was treated with the product of the two extract methods (aqueous or methanol extract method). This treatment was done in 
absence or presence of eco-friendly crosslinking agent. Firstly, the cotton fabric was treated with herbal extract by dip method. The fabric was immersed in the two extract herbs for $30 \mathrm{~min}$ and dried. Then the finished cotton fabric was subjected for the antimicrobial assessment. Seeondly, the cotton fabric was treated with the two previous herbal extract in presence of ecofriendly crosslinking agent as follow: $2 \%$ of herbal extract was mixed with $6 \%$ of glyoxal as crosslinking agent and $4 \%$ aluminum sulphate $\mathrm{Al}_{2}\left(\mathrm{SO}_{4}\right)_{3}$ was added as a catalyst. Cotton fabric was padded dip and nip in the finishing formula and then the treated fabric was dried at $80^{\circ} \mathrm{C}$ for $5 \mathrm{~min}$. and cured at $120^{\circ} \mathrm{C}$ for $3 \mathrm{~min}$.

\section{Washing cycle procedure}

The antibacterial activity of the finished fabric was evaluated after subjected to several washed cycles. The finished fabrics were washed using non ionic detergent $2 \%$ owf at $40^{\circ} \mathrm{C}$. keeping the material to liquor ratio at 1: 50 followed by rinsing washing and drying.

Antimicrobial activities assessment

Antibacterial activities and antifungal of

TABLE 1. Different kind of bacteria and fungus used in evaluation.

\begin{tabular}{|c|l|l|}
\hline No & & \multicolumn{1}{|c|}{ Source } \\
\hline 1 & Escherichia Coli 8739 & \\
2 & Salmonella tyhemurum 14028 & \\
4 & Bacillus Subtilise 6633 & \\
5 & Sacillus cereus 33018 & American Type Culture Collection \\
6 & Candida albicans 16231 & \\
7 & Candida tropical's 750 & \\
8 & Candida pseudo tropical's 2512 & \\
9 & Sacctaromyces Chevalier 9804 & \\
\hline
\end{tabular}

crude extract were tested in vitro against different microorganisms including gram negative bacteria (salmonella tyhimurium, Escherichia Coli) and the gram positive bacteria bacillus subtilis, bacillus cereus, staphylococcus aureus and yeasts unicellular fungi (candida albicans) as shown in Table 1 .

\section{Antimicrobial assay}

The antimicrobial activities of the crude extract were determined using agar plate as follow. The plates were incubated at $37^{\circ} \mathrm{C}$ for $24 \mathrm{~h}$ a growth free zone of inhibition around the fabric appears as antibacterial agent migrates from the fabric onto the agar and diffuses outward. Diameter of inhibition zone was determined according to AATCC test method 100-199 [11] . different kind of bacteria and fungus were used in the evaluation step and it is listed in insert Table 1

\section{Characterization of treated fabric}

- The surface morphology of treated fabrics was established by using scanning electron microscope (SEM)

- Tensile strength and elongation at break one of the important physical parameters, of treated and untreated fabrics was evaluated by strip method according to ASTM test method breaking load and elongation of textile fabric D1682-94 [12]

- Abrasion Resistance

- Water \& air permeability

- $\quad$ Stiffness of the fabric

- Antibacterial \& antifungal properties of the treated fabric

- UV protection factor: UV-vis spectrum was recorded on Perkin Elmer Lambda 3BUVVis spectrometer. Ultraviolet protection factor (UPF) was measured using UV Shi- 
madzu 3101 PC-Spectrophotometer. UV Protection and classification according to AS/ NZS 4399:1996 were evaluated.

\section{$\underline{\text { Results and Discussion }}$}

Cotton fabric was finished with herbal extraction of chamomile, sage and green tea without using any source of chemicals. These herbs are applied directly to the fabric in presence of crosslinking agent glyoxal and aluminum sulphate as a catalyst. In this study it was proved that the plant extracts could be effective against

1-Structural formula of Chamomile in Apigenin is one of flavonoids

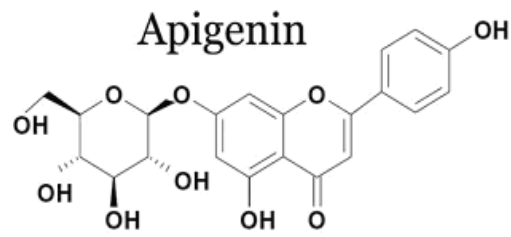

2-Structural the main component of sage is phenyl propanoids<smiles>O=C(/C=C/c1ccc(O)c(O)c1)OC1CC(O)(C(=O)O)CC(OC(=O)/C=C/c2ccc(O)c(Cl)c2)C1O</smiles>

3-Structural formula of the main component of green tea is catechin<smiles>Oc1cc(O)c2c(c1)O[C@H](c1ccc(O)c(O)c1)[C@H](O)C2</smiles>

\section{Structures}

both + Ve \&-Ve bacteria and yeast (unicellular fungi). These are resulted to the main component of the plant extract.

\section{Tentative mechanism}

As already indicated the natural plant Chamomile, sage and green tea is developed of different constituents many of which have functional groups.

1. Chamomile, sage, green tea with crosslinking agent were formed an insoluble products, which becomes bonded through hydrogen bonding, another force in these bonding are physical forces.

2. Chemical bonded between plant molecule and cotton cellulose molecules with crosslinking agent acting as a bridge that is, as the crosslinking agent is bi or polyfunctional, allows it to chemically react with the hydroxyl group in plant and cellulosic structure. It is logical that, physico mechanical together with chemical attachment of plant extract to cellulosic fibre and finishing agent, affect the antibacterial activity. the aforementioned reaction may be represented by the mechanisms suggested by the equation as follows:[13]

Identification test for active compounds

The chamomile plant classified from teraceae family and is known as common medicinal plant. The therapeutic activity of chamomile can be attributed to presence of different effective substances such as phenolics, flavonoid, Apigenin, querretin, patuletin, luteolin and glucosides [14]. The chamomile extract has also antibacterial and antifungal activity, which refers to the flavonoid, apigenin.

Green tea is a natural material and has many beneficial characteristics on human. Green tea has an active phenolic moiety (called catechin) in its extracted components. It is structure have various powerful substances, for example, $(+)$ catechin, (-) epi catechin (EC), (-) epigallocatechin (EGC),(-)epicatechin gallate (ECG),(-) epigallo catechin gallate (EGCG), (-)gallocatechin gallate (GCG) [15] .

As the green tea contains catechin and polyphenols which have been found to possess antibacterial and antiviral action as well as anticarcinogenic and antiutagenic properties, it has also antibacterial activity that includes inhibition of gram positive and gram negative [16].

Sage (salvia species), the genus salvia, commonly called sage, the plants are mostly aromatic with flower in different colors which have been used as traditional herbal medicine [17]. Sage extract has some chemical compounds such as flavonoids, terpenoids and essential oils. Essential oils are important for the monitoring of anticancer, antimicrobial, antioxidant, and free radical. In addition, Sage is characteristic as source of different flavonoids polyphenolic 


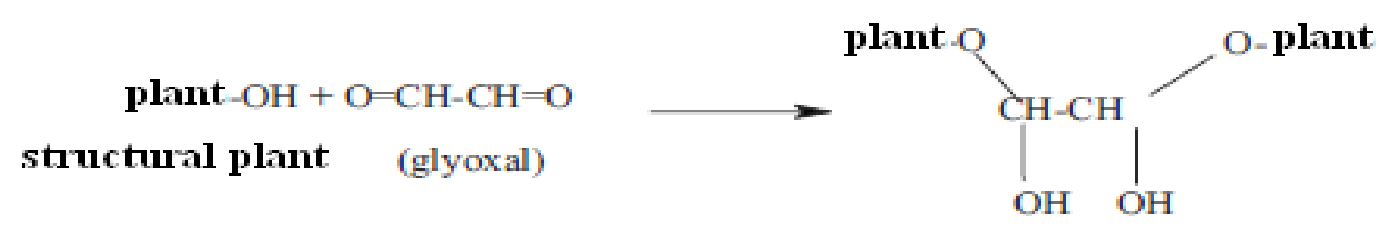

(crosslinked plant )
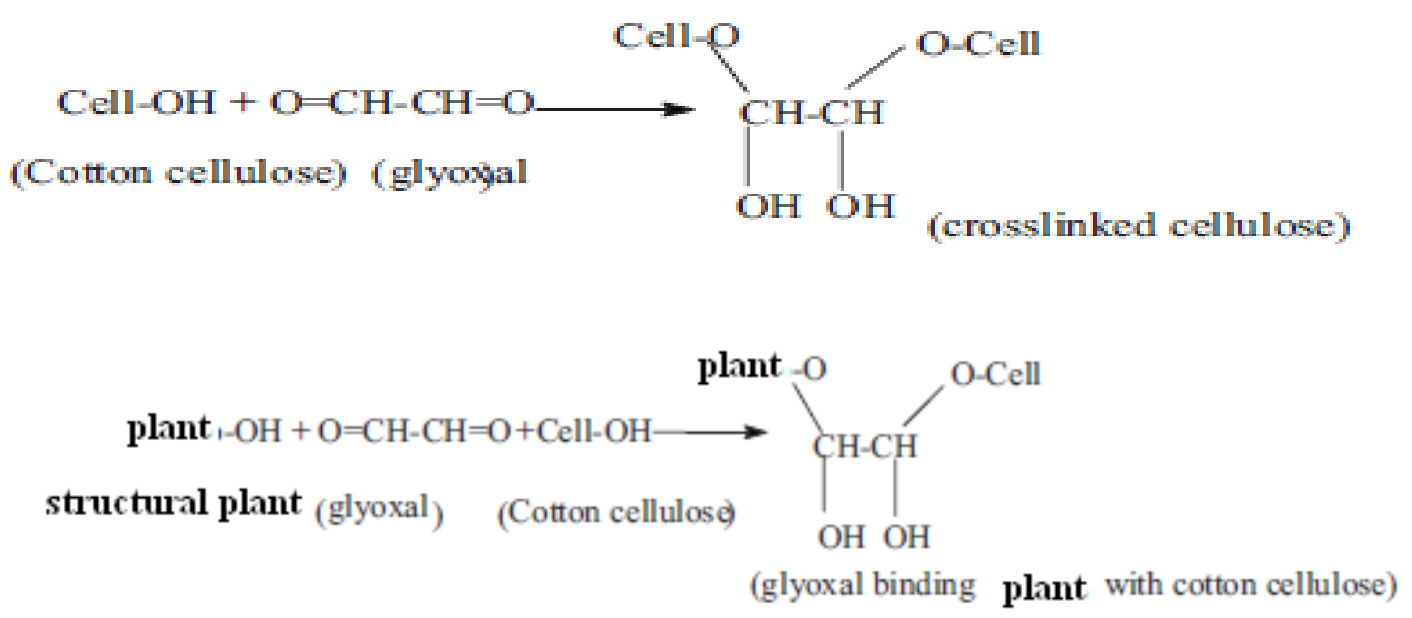

Tentative mechanism

compound such as carnosic, rosmarinic and coffeic acids, which providing as antioxidant and antibacterial.

The antibacterial effect of sage demonstrates that, the aqueous extract has significant activity especially against B.subtilies, B. mycoids. This extract can be also used in biotechnological field such as food industry [18].

Furthermore, the antibacterial activities of sage essential oils exhibited a better efficiency than antibiotics against bacteria; especially against resistant bacteria to the antibiotics, which provide the sage essential oils better than traditional antibiotics. From the results, it is clear that, sage plants containing largest number of bioactive compounds, which have a wide range of organic biological, activates. There can exhibit antiinflammatory, antioxidant, antimicrobial and antiviral effects[19,20].

Antimicrobial activity of sage aqueous extracts

In this study the aqueous extract of chamomile, sage, and green tea has no activity seen against the gram positive bacteria and gram negative bacteria except for the green tea has an effect for salmonella typhimuriure which the zone of inhibition was $15 \mathrm{~mm}$, and there is no activity for the fungi.
Antimicrobial of methanol extract

Chamomile, sage and green tea extract $(2 \%)$ when directly applied on cotton fabric along with glyoxal (crosslinking agent) $6 \%$ and $\mathrm{Al}_{2}\left(\mathrm{SO}_{4}\right)_{3}$ as a catalyst $4 \%$. The treatment was carried out through pad-dry-cure method with $100 \%$ wet pickup, drying at $100^{\circ} \mathrm{C}$ for $5 \mathrm{~min}$ and curing at $120^{\circ} \mathrm{C}$ for $3 \mathrm{~min}$.

Table 2 explains the effect of plant concentration on the antibacterial and antifungal activities. It is demonstrate that, the chamomile has an activity only for Candida tropical 750 (fungi) but the sage has an activity for gram positive bacteria (B.subtilies, B. Cereus, Staph. aureus) but there is no activity for gram negative (E- Coli, salmonella typhimurium) and has more activity for uni-cellular fungi (Candida albicans, Candida tropical's and Candida pseudo tropical's). However, the green tea has an activity for B- Cereus gram-positive bacteria and for Candida albicons (fungi). It was observed that the inhibition zone of sage treated sample was higher than chamomile and green tea for the positive gram bacterium and antibacterial activity for the fungi. The antibacterial and antifungal properties of sage increases than the chamomile and green tea, which results from presence of active 
TABLE 2. Effect of methanol extracts of chamomile, sage and green tea on the bacterial and fungal activities.

\begin{tabular}{|l|c|c|c|c|c|c|}
\hline \multirow{2}{*}{ Microorganisms } & \multicolumn{5}{|c|}{ Inhibition Zone (mm) } \\
\cline { 2 - 7 } & \multicolumn{2}{|c|}{ Chamomile } & \multicolumn{2}{|c|}{ Sage } & \multicolumn{2}{c|}{ Green tea } \\
\cline { 2 - 7 } & $\mathbf{1 \%}$ & $\mathbf{2 \%}$ & $\mathbf{1 \%}$ & $\mathbf{2 \%}$ & $\mathbf{1 \%}$ & $\mathbf{2 \%}$ \\
\hline B subtilies 6633+ve & 0 & 0 & 15 & 25 & 0 & 0 \\
B Cereus 330018+ve & 0 & 0 & 15 & 25 & 10 & 15 \\
Staph-aureus 25923+ve & 0 & 0 & 14 & 14 & 0 & 0 \\
E coli 10 23 -ve & 0 & 0 & 0 & 0 & 0 & 0 \\
Salmonella typh. -ve & 0 & 0 & 0 & 0 & 0 & 0 \\
Candida albicans 10231 & 0 & 0 & 18 & 25 & 8 & 10 \\
Candida fungi tropical's7 50 & 20 & 28 & 16 & 20 & 0 & 0 \\
Candida pseudo tropical's 2512 fungi & 0 & 0 & 20 & 25 & 0 & 0 \\
\hline
\end{tabular}

component in large amount these substances e.g.(anthraquinones, flavonoids, saponins, tannins and polysaccharides) that have antibacterial and antifungal activities. these substances have the ability to bind adhesions, complex with cell wall, inactivate enzymes, denaturing proteins and disrupt the membrane to limit the growth of microbes by disabling cell functioning or reproduction.[21]

Figure 1 shows that the treatment of cotton fabric treated along with crosslinking agent has a good resistance to bacterial attack and also antifungal. From the table the antimicrobial activity was assessed by measuring the inhibition zone diameter chamomile and sage showed the highest inhibition zone diameter than the green tea against gram positive bacteria and fungi. But there is no activity against gram negative bacteria (E-coli) and they are of the opinion that the gram + ve bacteria are more susceptible to natural plant extract compared to gram-negative bacteria.

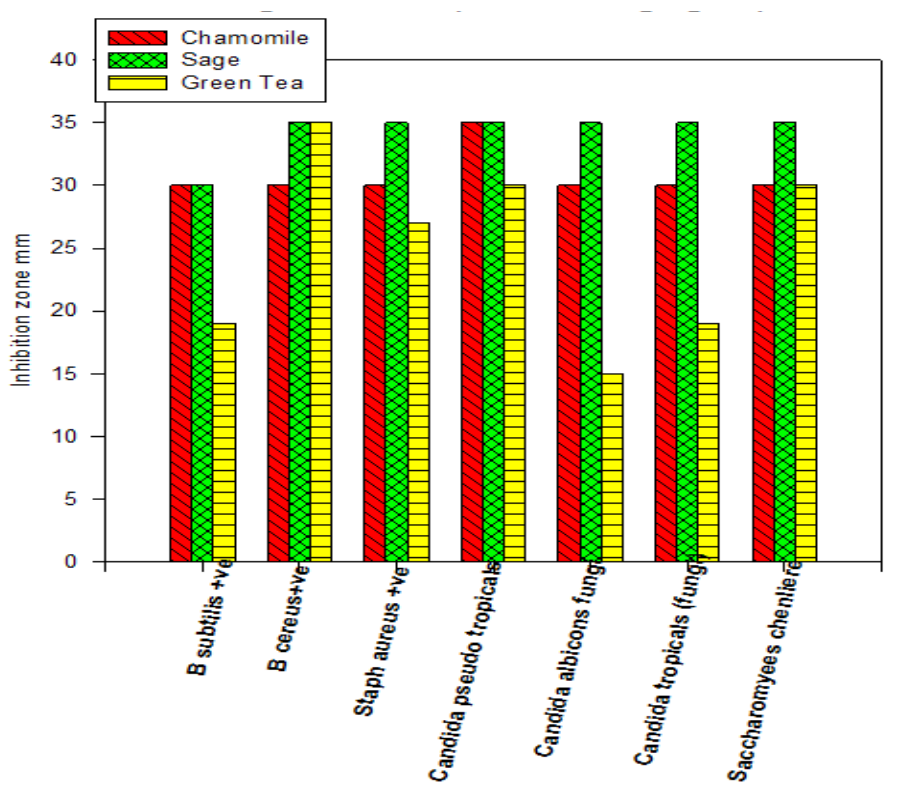

Fig.1. Antimicrobial properties of chamomile, sage and green tea extracts along with resin (crosslinking agent). 
The effects of the plant extracts against both gram positive, gram-negative bacteria and fungi was depending on components type in the plant extract[22]. Recently, many researchers have studied the mechanism of the antimicrobial effect on textiles fibers, and indicated that the fiber surface bonded to antimicrobial agents, which disrupt the cell membrane of the microorganisms by an electrochemical mode of action[23,24].

Table 3 shows the inhibition zone diameter before washing and after 5,10 washes cycles by using nonionic detergent $(5 \mathrm{~g} / \mathrm{l})$ at $40^{\circ} \mathrm{C}$ for $30 \mathrm{~min}$, followed by rinsing drying. It was found that the herbal extracts with crosslinked provide a good wash durability up to 10 -wash cycle. This may be due to the crosslinking of the herbal extract with glyoxal, which improves the wash fastness property. Chamomile, sage, and green tea extracts were applied directly to the fabric using a paddry-cure process method.

TABLE 3. Effect of washing durability of chamomile, Sage and green tea treated cotton fabric along with crosslinking agent

\begin{tabular}{|c|c|c|c|c|c|c|c|c|c|}
\hline \multirow[b]{2}{*}{ Wash cycle } & \multicolumn{3}{|c|}{ Chamomile } & \multicolumn{3}{|c|}{ Sage } & \multicolumn{3}{|c|}{ Green tea } \\
\hline & zero & 5 & 10 & zero & 5 & 10 & zero & 5 & 10 \\
\hline \multicolumn{10}{|l|}{ Microorganism } \\
\hline B subtilis & 30 & 27 & 24 & 30 & 25 & 19 & 19 & 15 & 9 \\
\hline Bcereus & 30 & 27 & 23 & 35 & 30 & 19 & 35 & 30 & 20 \\
\hline Staph aureus & 30 & 25 & 22 & 35 & 25 & 15 & 27 & 20 & 15 \\
\hline Candida albicons & 35 & 25 & 22 & 35 & 25 & 15 & 30 & 25 & 20 \\
\hline Candida tropicals & 30 & 20 & 15 & 35 & 25 & 14 & 15 & 10 & 8 \\
\hline Candida pseudo tropicals & 30 & 20 & 15 & 35 & 22 & 15 & 19 & 10 & 8 \\
\hline Sacctaromyces chevalier 9804 & 30 & 25 & 20 & 35 & 30 & 20 & 30 & 25 & 15 \\
\hline
\end{tabular}

The main confinement is that the treatments of fabric with the extract have poor wash durability. So, the fabric can be used such as disposable items for single application such as surgical bandage, which not needs to be washed. Some applications are required several washes such as bed linen sheet in hospital, socks, garments apparels are worm by consumers. The treated fabric with herbal extract with cross linking-agent, shows good resistance to bacteria and fungi attack.

\section{Evaluation of physical properties of finished cotton fabric}

It is observed that the tensile strength decrease with crosslinking alone where the tensile strength of extracts finished fabric along with crosslinking showed slightly higher. This was mainly due to the organic molecules of the extracts adsorbed in the voids of the fabric which helps to resistance of the tensile load on stress and there is also for the elongation.

-Abrasion resistance test was determined the ability of a fabric to withstand damage by friction. The abrasion resistance of the treated cotton fabric with extracts along with crosslinking agent showed higher than the blank treated with crosslinking alone. The results indicate that the treated fabrics are resistance to abrasion of organic molecules adsorbed in the voids of the fabric, which helps to wear and tear[25].

-Air permeability which ultimately tested to decide the comfort properties showed interesting phenomenon the air permeability showed relatively low than the untreated and treated with crosslinking agent alone. This may be due to the size of herbal particles get block the pores of fabrics

Egypt.J.Chem. 61, No. 2 (2018) 
-Water permeability of the treated fabric is decreased than untreated cotton fabric and treated cotton fabric with crosslinking alone. This is because of the hydrophobic nature of plant extract, which forms thin film on the fabric surface. The results shown in Table 4 indicated that the roughness of treated fabric was decreased than the untreated fabric, due to the coating of fabric by herbal extract.

\section{Ultraviolet (UV) protection factor}

Ultraviolet (UV) radiation falls into three main categories a) longer wavelength/low energy fraction (UV-A; $\lambda=320-400 \mathrm{~nm}), b$ ) shorter wavelength/high energy fraction (UVB; $\lambda=280-320 \mathrm{~nm})$, and $\mathrm{c})$ the highest energy fraction (UV-C; $\lambda<280$ ), that is UV-B can result in the greatest skin damage [14]. Textiles have been considered a primary tool in shielding UVR cotton the most preferable fiber type worn during the summer, provides a relatively low UV protection, especially in case of thin cotton having a low fabric count. Table 5 shows the effect of ultraviolet protection factor (UPF) of treated cotton fabric with herbal extract of chamomile, sage and green tea along with the glyoxal as crosslinking. It is clear that, the data in Table 5 provide that the fabric treated with green tea in presence of crosslinking agent improve UPF value when compared with other natural plant chamomile and sage. Green tea dyeing the fabric and employed to increase UV protection property of cotton. Green tea has an active phenolic moiety called catechin, which exert a proper UV protective property natural extract with crosslink.

Therefore using green tea extract is enhancing UV protection property of cotton would be novel method in terms of biocompatibility and physiological benefits and in addition, it can be done environment-friendly way, to study more to increase the caterhin because both components would exist in anionic forms in aqueous solution, so a mordanting agent will be needed [26].

\section{SEM of treated cotton fabric}

SEM photographs of cotton treated fabric

TABLE 4.The difference in the physical properties of the cotton treated with chamomile, sage, green tea extracts along with crosslinking agent.

\begin{tabular}{|c|c|c|c|c|c|c|}
\hline Sample & $\begin{array}{c}\text { Tensile } \\
\text { strength } \\
\text { Kg }\end{array}$ & Elongation \% & $\begin{array}{c}\text { Abrasion } \\
\text { resistance }\end{array}$ & $\begin{array}{c}\text { Air } \\
\text { permeability } \\
(\mathbf{c c} / \mathbf{s e c} / \mathbf{c m})^{2}\end{array}$ & $\begin{array}{c}\text { Water } \\
\text { permeability } \\
\mathbf{L} / \mathbf{m}^{2} / \mathbf{s e c}\end{array}$ & Roughness \\
\hline Blank & 55 & 18 & 311 & 35.5 & 0.328 & 17.6 \\
\hline B- & 31 & 13 & 158 & 30.77 & 0.313 & 16.6 \\
\hline B-Chamomile & 38 & 15 & 233 & 31.65 & 0.305 & 17.15 \\
\hline B-Sage & 39 & 15 & 210 & 27.27 & 0.282 & 15.23 \\
\hline B-Green tea & 40 & 16 & 200 & 27.27 & 0.269 & 14.75 \\
\hline
\end{tabular}

Blank, cotton fabric, untreated, B- cotton fabric treated with crosslinking agent +catalyst (pad-dry-cure).

TABLE 5. UPF values of cotton fabric treated with herbal extract of chamomile, sage and green tea along with glyoxal as crosslinking agent

\begin{tabular}{|l|c|c|}
\hline Sample & UPF rating & Protection level \\
\hline Blank & 2.9 & Poor \\
\hline Chamomile & 11.1 & Moderate \\
\hline Sage & 6.1 & Poor \\
\hline Green tea & 21 & Good \\
\hline
\end{tabular}

UPF Protection levels: a) poor $(\mathrm{UPF}<10)$, b) moderate $(10<\mathrm{UPF}>30)$, c) very good $(30<\mathrm{UPF}>40)$ and $d)$ excellent (UPF $>40)$

Egypt.J.Chem. 61, No. 2 (2018) 


\begin{tabular}{|c|c|c|c|}
\hline Extract herbs & Without crosslinking & With crosslinking & Blank cotton \\
\hline \multicolumn{4}{|l|}{ Chamomile } \\
\hline \multicolumn{4}{|l|}{ Sage } \\
\hline \multicolumn{4}{|l|}{ Green tea } \\
\hline & & & \\
\hline
\end{tabular}

Fig. 2. SEM of cotton treated with Chamomile, Sage and Green Tea in presence and absence of crosslinking agent.

with the extract herbal are shown in Fig. 2. It is clear that the dip sample, either treated with the extract herbs alone or in presence of crosslinking agent samples are bonded well to the fabric surface even after 10 washes. The presence of crosslinking agent is clearly showed in the SEM figure that fixed the extract herbs on cotton fabric even for the fabric treated with extract herbs alone the SEM showed smooth surface coating on cotton fabric.

\section{Conclusion}

The essential aim of the present study was the exploration of anti-microbial properties of Chamomile, Sage and Green tea extracts on cotton fabric, advent a new technology in consumer needs. The net results of this study were showed that the specimens treated with the extract in presence and absence of crosslinking agent have excellent disinfection properties. The treated sample showed high decrement in colonies grown and a clear zone of bacteria inhibition for crosslinking fabric than the other. the durability of the treated fabric to antimicrobial property was $35 \mathrm{~mm}$ after 10 washing cyclic with acceptable physical properties including Abrasion resistance, Air permeability, Water permeability and good results for UV protection.

\section{Acknowledgment}

The authors would like to acknowledge and express their gratitude to In-house Project Office at National Research Centre of Egypt to fund this research and facilitate all the capabilities to finish this work under project ID \#11090323

\section{References}

1. Sathianarayanan M.P. Antibacterial finish for cotton fabric from herbal products. Indian Journal of Fibre \& Textile Research, 50, 35, (2010).

2. Hashem M., El-Shafei A., Sharaf S., Zaghloul S., Development of Softener Containing Metal Nano-Particle for Multipurpose Textile Finishing, International Journal of Pharm Tech Research.,123,8 (10), (2015) .

3. Samanta A.K., Agarwal P., Application of natural dyes on textiles, Indian J. Fiber Text. Res., 384,34, (2009). 
4. Specos M.M., Garcia J.J., Tornesello J., Marinoa P., Vecchia M.D., Tesoriero M.V.D., Hermida L.G., Microencapsulated citronella oil for mosquito repellent finishing of cotton textiles, Trans. R. Soc. Trop. Med. Hyg., 653,104 (2010).

5. Sricharussin W., Sopajaree C., Maneerung T., Sangsuriya N., Modification of cotton fabrics with $\beta$-cyclodextrin derivative for aroma finishing, $J$. Tex., 682,100 (2009).

6. Grifoni D., Bacci L., Zipoli G., Albanese L., Sabatini F., The role of natural dyes in the UV protection of fabrics made of vegetable fibres, Dyes Pigm., 279, 91 (2011).

7. Sun S., Tang R., Adsorption and UV protection properties of the extract from honeysuckle onto wool, Ind. Eng. Chem. Res., 4217, 50 (2011).

8. Shahid M., Ahmad A., Yusuf M., Khan M.I., Khan S.A., Manzoor N., Mohammad F., Dyeing, fastness and antimicrobial properties of woolen yarns dyed with gallnut (Quercus infectoria Oliv.) extract, Dyes Pigm., 53, 95 (2012).

9. Huang L., Gerber M., Lu J., Tonelli A.E., Formation of a flame retardant cyclodextrin inclusion compound and its application as a flame retardant for poly (ethylene terephthalate), Polym. Degard. Stab., 279, 71 (2001).

10. Bouchekrit H., Aazy M., Nasri M., essential oils from Elaeoselinum asclepium: chemical composition, antimicrobial, and antioxidant properties. Asian Pacific Journal of Tropical Biomedicine, 7 (2016).

11. Behroz, Otealleh, Payam Zahedi, Iraj Kezaeian, Morphology, drug release, antibacterial cell proliferation, and histology studies of chamomile loaded wound dressing mats based on electrospun nanofibrous poly (caprolactone)/polystyrene blend J.Bioed Mater Res part B00B, (2013)

12. AATCC Test Method (100-2012), Assessment Of Antimicrobial Finishes On Textile Materials, in Technical Manual Method, American Association of Textile Chemists and Colorists (2012).

13. ASTM Standard Test Method C33 (ASTMD-16822011), Standard Test Methods for Determination of Tensile Strength., ASTM International: West Conshohocken, PA (2011).

14. Sharaf S., Higazy A., Hebeish A., Propolis induced antibacterial activity and other technical properties of cotton textiles. International Journal of Biological Macromolecules, 408,59 (2013).

Egypt.J.Chem. 61, No. 2 (2018)
15. Kim H., Dyeing characteristics and UV protection property of green tea dyed cotton fabrics - Focusing on the effect of chitosan mordanting condition. Fibers and Polymers, 255, 7(3), (2006).

16. Latteef N.S., Phytochemical, Antibacterial and Antioxidant Activity of Camellia Sinensis Methanolic and Aqueous Extracts. Journal of Pharmacy and Biological Sciences, 113,11(6), (2016).

17. Noor S., Latteef. Phytochemical, Antibacterial, Antioxidant Activity of camellia sinens is Methanolic and aqueous extracts. J Of Pharmacy And Biological Science 13,11(6), (2016).

18. Hamidpour R., Sage: The functional novel natural medicine for preventing and curing chronic illnesses. 671,4 (2013).

19. Khalil R., Li Z.G., Antimicrobial activity of essential oil of Salvia officinalis L. collected in Syria. African Journal of Biotechnology, 10,42 (2011)

20. Bishnu Joshi, Govind Prasad Sah, Buddha Bahadur Basnet, Megh Raj Bhatt, Dinita Sharma,Krishna Subedi, Janardhan Pandey and Rajani Malla; Phytochemical extraction and antimicrobial properties of different medicinal plants: Ocimum sanctum (Tulsi),Eugenia caryophyllata (Clove), Achyranthes bidentata(Datiwan) and Azadirachta indica (Neem). Journal of Microbiology and Antimicrobials 1,3(1) (2011).

21. Oancea1.A Roată G. S. Popescu S.,I. Mateescu Toma1 I. A. E. Gaspar A., Sidoroffphytochemical M.Screening Of The Bioactive Compounds In The Most Widespread Medicinal Plants From Calarasi - Silistra Cross Border Area; Agricultural Food Engineering 6 (55) No. 2 (2013).

22. Joshi M.et al., Ecofriendly antimicrobial finishing of textiles using bioactive agents based on natural products. IJFTR, 295, 34 (2009).

23. Sarkar R.K., Purushottan D.E., Chauhan P.D., Bacteria- resist finish on cotton fabric using natural herbal extracts. IJFTR, 322, 28 (2003).

24. Jothi D. Experimental study on antimicrobial activity of cotton fabric treated with aloe gel extract from Aloe vera plant for controlling the Staphylococcus aureus (bacterium) African Journal of Microbiology Research 228, 3(5) (2009).

25. Hebeish A., El-Shafei A., Sharaf S., Zaghloul $\mathrm{S}$, In situ formation of silver nanoparticles for multifunctional cotton containing cyclodextrin, 
Carbohydrate Polymers 422,103 (2014).

26. Ibrahim N.A. et al., Proper finishing treatments for sun-protective cotton-containing fabrics. Journal of Applied Polymer Science, 1024, 97(3) (2005).

(Received 11/1/2018;

\title{
مادة مستخلصة من الاعشاب لمعالجة الاقشة القطنية ضد الميكروبات

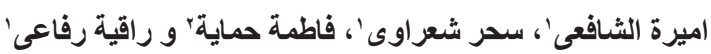

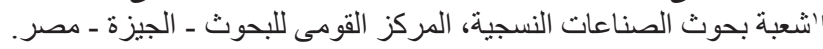 r شعبة بحوث الهندسة الور اثية و البيوتكنولوجى، المركز القومى للبحوث ـ ـ الجيزة ـ مصر.
}

\begin{abstract}
تم تحضير مادة امنة بيئية مستخلصة من مستخلصات الاعثاب الطبية و لها استخدامات متعددة. تم معالجة الإنة

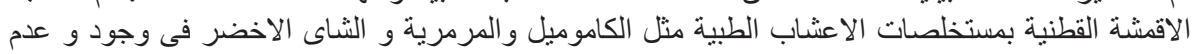

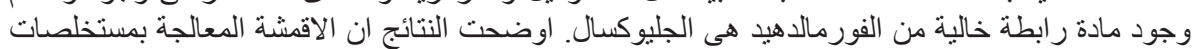

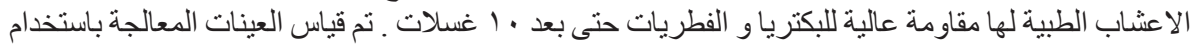
SEM

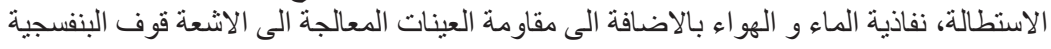

